
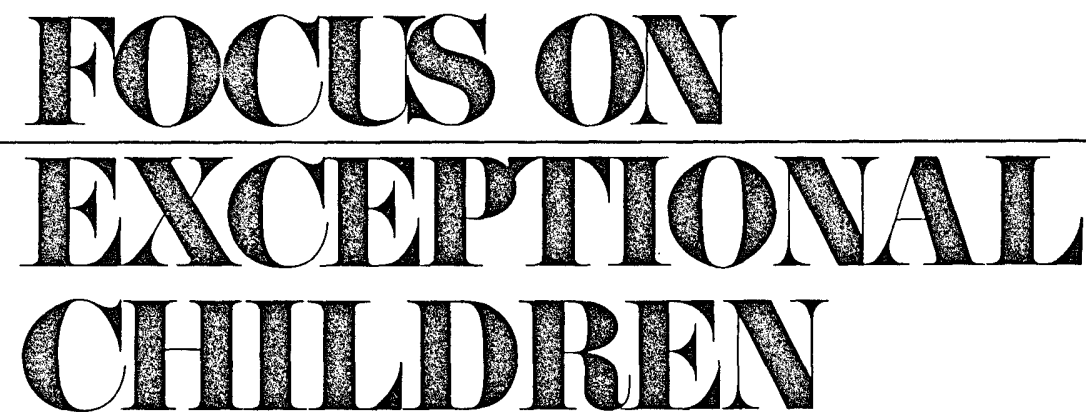

\title{
Mathematics for Handicapped Learners: A Functional Approach for Adolescents
}

\author{
Stuart E. Schwartz and Diane Budd
}

James, a typical high school student in a program for educable mentally retarded pupils, was frustrated by the task of learning to measure. His classroom teacher, an experienced and creative person, had used many different activities and reinforcement methods in an attempt to teach Jim to measure, but Jim had made no progress for months.

The work-study teacher took Jim to the area vocational school one day and after a visit around the center, Jim decided he wanted to be a carpenter's helper. In response to Jim's questions, the carpentry teacher replied, "No, you don't have to be a good reader to be a carpenter, but you've got to be able to measure."

Jim returned to class and told his teacher of his need to learn to measure. The teacher continued to use the same methods as before but applied these to functional carpentry tasks. Jim now had a reason to learn, and he and his teacher succeeded in two weeks' time.

Andrea, a hard-of-hearing teenager, was not interested in school, was simply putting in her time, and was failing math. She had been required to memorize math facts for the four basic math functions.

The girl knew she wanted to get married and rear children someday. When the math teacher told his class of academically deficient students that they were no longer going to study math but, rather, the use of numbers in home and child care, Andrea became excited. She began to hear about home budgets, buying food, banking, and other useful topics. For the first time in a long while, Andrea liked school - well, at least she liked math class, because she had a reason to learn.

Stuart Schwartz is an associate professor in the Department of Special Education and Diane Budd is a research assistant and doctoral student, both at the university of Florida. 
Hundreds of additional true stories about mildly handicapped adolescents and their frustrations with arithmetic can be told. Educators have long been concerned about the best content and procedures in mathematics instruction for mildly handicapped learners. This article deals with functional mathematics for adolescents with mild learning handicaps. It suggests content, materials, and procedures. First, however, a definition of functional math for handicapped students is necessary. Functional math refers to the study of uses of mathematics needed for vocational, consumer, social, recreational, and homemaking activities. Functional math includes the application of those uses. Therefore, a functional math program is designed to teach mildly handicapped pupils two important concepts: (a) how math will help them be successful adults, and (b) how to use math to be successful adults. Functional math involves not only the teaching of arithmetic computational skills; it means teaching the use of arithmetic to solve everyday problems.

\section{WHY FUNCTIONAL MATH?}

One current topic that pervades newspapers, magazines, television news shows, and conversation throughout our nation is the spiraling rate of unemployment.

FOCUS ON EXCEPTIONAL CHILDREN (ISSN 0015-5IIX) (USPS 203-360) is published monthly except June, July, and August as a service to teachers, special educators, curriculum specialists, administrators, and those concerned with the special education of exceptional children. This journal is abstracted and indexed in Exceptional Child Education Resources, and is also a vailable in microform from Xerox University Miçrofilms, Ann Arbor, Michigan. Subscription rates, $\$ 13.50$ per year. Copyright 1981, Love Publishing Company. All rights reserved. Reproduction in whole or part without written permission is prohibited. Printed in the United States of America. Second class postage is paid at Denver, Colorado. POSTMASTER: Send address changes to:

$$
\begin{aligned}
& \text { Love Publishing Company } \\
& \text { Executive and Editorial Office } \\
& 1777 \text { South Bellaire Street } \\
& \text { Denver, Colorado } 80222 \\
& \text { Telephone (303) 757-2579 }
\end{aligned}
$$

\section{EDITORIAL BOARD}

Edward L. Meyen University of Kansas

Richard J. Whelan

University of Kansas Medical Center

Carolyn Acheson

Senior Editor
Stanley F. Love Publisher
The Statistical Abstract of the United States (U.S. Department of Commerce, 1979) showed an overall unemployment rate of 5.8 percent for American workers during 1979 . For the teenaged population (16-19 years) the unemployment figure was 16.1 percent. One only has to read daily newspapers to realize that unemployment problems continue to exist. A large percentage of the nonhandicapped population appears to be having great difficulty obtaining and maintaining employment. This situation is magnified for handicapped youth who, as a group, experience even greater unemployment or underemployment (Martin, 1972). In order to compete with nonhandicapped peers in the job market, they must become equipped with as many technical and employability skills as possible.

The principle of normalization advocates that handicapped persons attain as normal an existence as possible in the community. Academic skills, especially mathematics, provide the foundation for subsequent learning in both technical skills (e.g., carpentry, engine repair) and employability skills (e.g., budget management). Functional mathematics is a vital part of the continuum of skills leading to normal life.

As reflected in the Dictionary of Occupational Titles (U.S. Department of Labor, 1977), many occupations require the use of various levels of mathematics. Even in the rare instances when a job does not require math, the worker must know basic functional math in order to compute hours, wages, deductions, vacation and sick leave hours, and other payroll-related tasks. This need is also reflected in work-study programs that contain both on-the-job training and regular academic curriculum. The regular academic curriculum should relate to the needs of the student on the job and, therefore, should include functional math as a necessary component (Rigger \& Rigger, 1980).

The concepts contained in career education also support the necessity to teach functional mathematics to handicapped youth. According to Brolin and Kokaska (1979), nine global competencies are required for the daily living skills deemed necessary for successful, independent living in society. The first of these nine is labeled "Managing Family Finances." Within this competency are five subcompetencies: (a) identify money and make change, (b) make wise expenditures, (c) obtain and use bank and credit facilities, (d) keep basic financial records, and (e) calculate and pay taxes. A review of these subcompetencies suggests that functional 
use of mathematics is a prerequisite for independent living and occupational skills that make up such a large part of successful adult adjustment. Each one of these functional mathematic subcompetencies can be analyzed and broken down into sequential tasks to be taught to the handicapped individual. The tasks may then easily become part of the student's individual education program.

Clark (1980) also sees career education as a means of making academics such as mathematics more meaningful and relevant. For instance, teaching subtraction and addition as they occur in the correct balancing of a checkbook or a savings account makes math relevant and meaningful. When learning tasks relate to recognized present needs or to perceived future needs, the tasks would seem more important to learn.

The concept of failure is a widely noted problem among handicapped learners. If a handicapped youth, however, has a good understanding of functional mathematics, that student will probably more often succeed in school and society. This skill may help diminish the fear of failure. For instance, if a student can become a wise consumer who makes appropriate personal expenditures, the student may be able to transfer that knowledge to the job situation and be more confident and competent when making decisions concerning business expenditures.

Vitello (1976) has reported that mentally handicapped youth have difficulty understanding math concepts contained within symbols. Several studies have indicated that functional math makes symbols and abstract information (such as one yard, one foot) more concrete, relevant, and meaningful (Sengstock \& Wyatt, 1976). For example, one often-used lab exercise in industrial arts involves constructing a tool tote according to planned specifications. This competency includes the concrete use of measurement skills and results in a product that makes those skills more meaningful to the student.

Buffer and Miller (1976) contend that functional mathematics stimulates and motivates underachievers and, therefore, achievement levels are improved by using a functional approach. Presenting such stimulation and motivation is the key reason for stressing the need for a functional mathematics program for handicapped students. Too often students have found the assignment of page after page of computations to be abstract and meaningless. Development of math skills based on relevant, concrete reasons provides the motivation for youth to see math as meaningful.

\section{A FUNCTIONAL MATH TEACHING SEQUENCE}

A number of authors (Krause, 1978; Peterson, 1973) have suggested math curricula for mildly handicapped learners. These curricula often contain the skills and methods for doing the basic arithmetic functions (addition, subtraction, multiplication, and division). The time required to teach these abstract skills is often lengthy. Mildly handicapped adolescents may not know why they are doing what they are doing, how an answer was obtained, or what an answer to a problem means. A functional math curriculum provides the answers to these problems.

Figure 1 depicts an eight-step sequence that is useful in initiating teaching strategies for a functional math curriculum. Methods for all these steps are discussed in the following paragraphs. The reader should consider
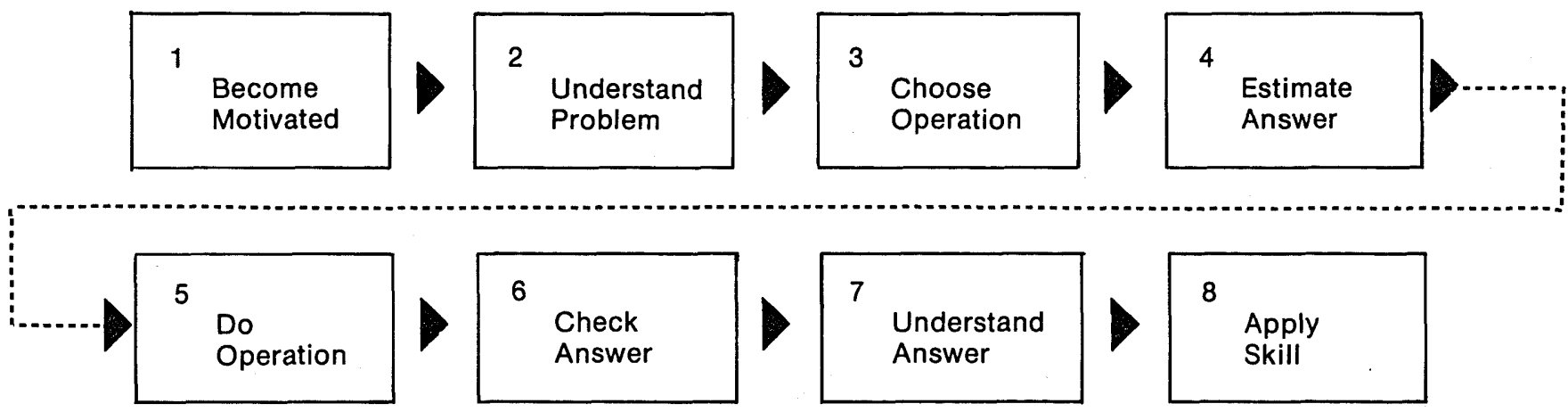

Figure 1

Functional Math Teaching Sequence 
the concreteness, realism, and functionalism of each step. Following that discussion is an outline of suggested content for a functional math curriculum.

\section{Step 1: Become Motivated}

The purpose of the initial phase of this functional math sequence is to help students become aware of how math will help them be better or more successful adults. School content must be relevant to the student's everyday needs (McDowell \& Brown, 1978) and to the student's perceived future needs. The entire career education movement that has been sweeping our schools strongly supports the need for motivation in terms of occupational and daily living skill preparation. If teachers are able to convince students of the math content's relevancy to present and future life, motivation to learn and gain skills should follow (Finn \& Brown, 1977).

This first step should help create an excitement for learning. The teacher who convinces students that they can use the functional math skills that are about to be taught is probably halfway to the goal of having excellent achievement among students.

\section{Some Suggested Strategies}

- Take students on field trips to various places of employment and have students analyze how math contributes to job success.

- Discuss the uses of math in the home.

- Establish a class store or business and discuss the need for arithmetic skills.

- Provide games reflecting real life stituations that require math to solve problems.

- Ask guest speakers, such as employers, to address the need for math skills among employees.

- Use instructional materials that demonstrate math usage for realistic problem solving.

- Visit vocational education classes and ask the vocational teachers to point out math skills needed for success.

- Have graduates talk to students about their use of math in the real world.

- Have students use math to solve everyday classroom or school problems.

- Relate all math instruction to real life situations.

\section{Step 2: Understand the Problem}

Students must understand the nature of the math puzzle or problem. To accomplish this, terminology must be clear, and students should be able to identify information provided within the problem and to determine what information is missing. Students must identify the question(s) posed within the problem. Then, thorough analysis of the question(s) being asked is needed. The students must also be able to determine which information is unnecessary.

If a teacher were to avoid or skip this step, students would be moving to a problem-solving component without adequate preparation. Students need to understand what is being asked before they can be expected to provide meaningful answers. They should be able to tell, at this point, what valuable information will be provided once an answer is determined.

\section{Some Suggested Strategies}

- Provide learning activities that define all new or difficult vocabulary. Be sure that the students understood all terminology.

- Use realistic problems for all discussions.

- Present problems and ask students to repeat those problems, exactly as they heard or read them. Then present the problems and ask students to repeat the problems using their own words.

- Provide activities that allow students to identify which parts of the information presented are not needed in order to solve the problem.

- Provide activities that allow students to identify which parts of the information presented are needed in order to solve the problem.

- Have students make up realistic math problems and present them to the class. Have classmates tell what they think the problems require.

- Provide exercises that require students to tell what the problems are asking. (Don't require students to mathematically solve problems at this time.)

- Use instructional materials that provide realistic problems, and have students verbally and schematically analyze those problems.

\section{Step 3: Choose the Operation}

Once students fully understand what the math problem is asking, the choice of which operation to use should be a somewhat easier step. But the students must first know what operations exist, what their symbols 
are, and what the operations actually do. Specifically, the students should know that addition exists and that addition combines items or groups of items. This example would be true for subtraction, multiplication, and division as well.

Knowledge of the existence of operations, recognition of symbols, and understanding of what the operations do is usually taught in early grades - before initiating a functional curriculum. The teacher has to determine if students have this prerequisite knowledge, and if a student is deficient in any of these skills, they should be addressed before proceeding with Step 3 .

\section{Some Suggested Strategies}

- Begin with simple thought problems. Have students state what question is being asked (Step 2). Tell the students what operation would solve the problem and explain why.

- Repeat the first strategy but have students choose the operation to solve the problem.

- Have students create math problems that can be solved by using a specific operation.

- Design worksheets that present problems and require the students to draw lines to the correct operation names and symbols.

\section{Step 4: Estimate the Answer}

This step is included to help students logically determine if their choice of operation is correct. It also assists students in checking their answers when the operation is completed.

After the student selects an operation, the teacher might assume that the student knows approximately what to expect as the outcome of the problem. This step may also allow the teacher to determine if the student knows approximately what the answer will be or at least can accurately predict the expected direction (larger/ smaller) of the answer.

If a student is unable to provide estimated answers that are, at a minimum, in the expected direction of the answer, he or she may not adequately understand the operation. Difficulty with the estimation may also indicate a lack of understanding of the problem or that, even though the choice of operation may have been correct, the wrong numbers were selected for that operation.

\section{Some Suggested Strategies}

- Teach students techniques for rounding off numbers.

- Introduce educational games that require students to guess (estimate) answers.

- Provide learning exercises that require only a choice of operation and answer estimation.

- Develop class exercises that give possible answers to questions and have students choose the most probable answer. Begin this activity with obvious answers, and then move up to more difficult choices.

\section{Step 5: Do the Operation}

In Step 5 the students actually do the operation using skills acquired in earlier grades. In traditional math classes students are often asked to immediately do an operation $(+,-, \times, \div)$ before having been formally taught the first four steps and given a chance to utilize them. This fifth step should follow the other four in sequence so the teacher is sure the students understand the mathematics exercises.

If any students need assistance with the operational procedures, the teacher can provide individual or group instruction, but only the students who need help should be included in this instruction. A good option is to provide electronic devices, tables of problems and answers, or manual materials. The focus in a functional curriculum is to provide meaningful, relevant math experiences. When certain students are unable to do operations fairly easily, they may tend to concentrate more on the operation than on why they are using the particular operation and what it should tell them. If students have learned all steps before this one, they should not be penalized for lack of skill with the operation but should be assisted in Step 5 so they will be able to proceed to Step 6. A device such as a battery-operated, hand-held calculator may be of great help in reducing the emphasis on the operation itself. Our society does not stigmatize people for using calculators; students can be taught to use calculators without fear of personal embarrassment.

The functional math program does not support the idea of presenting page after page of problems that simply provide practice in doing the operations. A math operation should take place to solve a realistic problem so that the operation is meaningful. 


\section{Some Suggesied Strategies}

- Provide a review of skills for doing the basic math functions with whole numbers, decimals, fractions, and percentages.

- Teach students how to use devices like tables or calculators to do operations. Such functions as entering numbers and copying readouts may require practice to improve students' accuracy.

- Be sure that adequate space immediately adjacent to written problems is available for doing operations.

\section{Step 6: Check the Answer}

After Step 5 has been accomplished, students must learn to check their answers. The aim is to ensure that numbers were copied correctly, that operations were performed correctly, and that the answers are logically correct.

To check the accuracy of their answers, students should be advised to repeat the operation in a different manner. If initially computed manually, for instance, the operation could be done on a calculator as a check. Or it could be checked again manually with numbers in reverse order (for addition and multiplication). Other procedures, such as multiplying the divisor by the answer to determine if it equals the dividend, could also be used.

To logically check answers, students should be taught to determine if their answers approximate their own estimates, as taught in Step 4. Step 7 will help this process as well.

\section{Some Suggested Strategies}

- Provide devices like calculators, rods, chips, or abaci for checking answers.

- Require students to show two ways to obtain their answers.

- Have students check other students' answers for accuracy and logic.

\section{Step 7: Understand the Answer}

After determining an answer in the form of a numerical response, the students should be taught to label and state its meaning. As stressed throughout, the usefulness of the math is critical, and without a label and statement of meaning, the numerical answer is a useless abstraction.

The label applied to the answer should actually evolve from Step 2, in which students establish what useful information is to be derived. Concluding the meaning of the answer may require discussion, including direct teacher questions like, "Just what does the answer mean to tell you?" Prompting and a refresher of Step 2 may be needed.

\section{Some Suggested Strategies}

- Remind students of their responses at the Step 2 stage.

- Develop and maintain a master list of possible labels for answers.

- Have students both write and verbally state the meanings of their answers.

- Use materials that require labels for all answers.

\section{Step 8: Apply the Skill}

This step applies the entire process to realistic, meaningful problems to reinforce the problem-solving skill and to demonstrate the usefulness of the skill. Practicing the first seven steps is important. If any step is skipped, the entire sequence may be threatened. Therefore, repetition or rehearsal of the complete process is vital.

As students practice the sequence, they should begin to realize how their ability to solve math problems has improved. Since realistic problems are involved, convincing students that this ability will be helpful to them should be easy.

\section{Some Suggested Strategies}

- Require students to practice the entire sequence of Steps 1-7 using materials and problems that are realistic and relevant.

- Be creative in developing problems.

- Have students develop problems based on their real life needs.

- Use a worksheet for problem solving. The worksheet shown in Figure 2 is useful in ensuring that students use all steps in solving functional math problems. 
1. Will knowing how to do this math help you someday?

Yes How?

No Ask your teacher how this math will help you.

2. Read the problem. What question is being asked?

3. What will the answer tell you?

4. Circle the one or ones you will use.

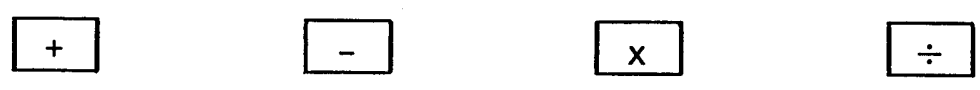

5. Estimate your answer. Use a label.

6. Do your math.

7. Put your answer here. Use a label.

8. Check your answer. Does your check agree with your answer? Yes No If yes, go ahead. If no, redo your math.

9. Is your answer close to your estimate? Yes No

If yes, go ahead. If no, think: Was your estimate wrong? Or is your answer wrong?

10. What does the answer tell you?

Figure 2

Problem-solving Worksheet

\section{FUNCTIONAL MATH CONTENT}

The outline of content suggested here is not exhaustive but is suggested as a starting point in a functional math program. Some content, such as number recognition and usage, does not require actual problem solving, just the application of meaning and use of the numbers.

\section{Consumer Skills}

\section{Making change}

Determining cost of sale items utilizing percentages (e.g., " $25 \%$ off")
Determining tax amounts

Doing cost comparisons

Buying on "time"

Balancing a checkbook

Determining total cost of purchases

Homemaking Skills

Measuring ingredients

Budgeting for household expenses

Calculating length of cooking and baking time when there are options (e.g., for a cake using two 9 " round pans vs. two 8 " round pans) 
Measuring material for clothing construction

Doing cost comparisons

\section{Health Care}

Weighing oneself and others

Calculating calorie intake

Determining when to take medication

\section{Auto Care}

Calculating cost of auto parts

Measuring spark plug gaps

Determining if tire pressure is correct

Figuring gas mileage

\section{Home Care}

Determining amount of supplies (paint, rug shampoo) to buy

Determining time needed to do projects

Measuring rods and drapes

Finding cost of supplies

Finding cost of repairs

\section{Vocational Needs}

Calculating payroll deductions

Determining money owed

Knowing when to be at work

Doing actual math for various jobs

\section{MATERIALS}

A cursory examination of publishers' catalogs of educational materials reveals many math materials; but a more in-depth look at secondary level materials shows that only a small portion of these materials presents math concepts in functional ways. Many materials give information in abstract ways that are difficult for handicapped students to comprehend (Budd, 1979).

In reviewing math materials for handicapped youth, teachers must be concerned with a variety of criteria. One area of concern is the actual academic content. Does it represent functional mathematics? Does it reflect competencies needed for independent living in the real world?

Another concern is the reading level of that content. Are comprehension and vocabulary levels appropriate for the handicapped individual? Many materials are considered to have a low reading level if the level is listed as 5.0 or 6.0 , but this may be altogether too complex for some handicapped students (Dunn, 1973). Some publishers do specify lower reading levels. Still, teachers should review these materials firsthand, looking specifically at the length and complexity of sentences and the number of syllables in words to ascertain if the stated reading level is accurate. Short, simple sentences and monosyllabic words are generally reflective of a lower reading level. If the teacher still has some doubt as to the actual reading level, the educator may use the "Fry Readability Chart" (Fry, 1977) or other reputable measures to determine the actual reading level.

Math problems are stated in many ways. If the reading level is too complex, it compounds the task and causes the student to have to decipher the words rather than solve the math problems. Beattie and Schwartz (1979) used the Fry system to examine a random sample of books used in special education classes. The results showed that the students, who were at an average second grade reading level, were confronted with sixth grade reading level textbooks. If the material does not reflect the stated reading level, the teacher may wish to review other materials or attempt to reconstruct the reading content so it is at an appropriate level.

Another concern regarding math materials for handicapped students is the availability of that material in both visual and auditory formats. Many visually impaired students have enough residual vision to be able to see an overhead projection of large, dark print. Hearing impaired students also benefit from visual presentation of math concepts. Some learning disabled students seem to do better if math is presented auditorially immediately after visual presentation of the same material.

The method and format used to present the material is also worthy of examination. For instance, a material that uses three dimensional money facsimiles or real money (as opposed to flat, two-dimensional pictures of money) may be better suited for functional mathematics presentations. Flat, pictorial representations alone have rarely been validated as effective teaching devices (Trace, Cuvo, \& Criswell, 1977).

Materials that include real objects are usually functional materials. Real-Life Math (Schwartz, 1977) is one example. This functional math kit includes real-looking checks, checkbooks, banking supplies, business forms, and business posters. Functional materials help provide the interest and motivation necessary for secondary level handicapped students. 
As educators review math materials for handicapped students, they should carefully examine the illustrations. Many times, handicapped role models are not represented well in materials. Handicapped youth may relate better to handicapped models who are functioning in the real world than to nonhandicapped models. Often, minority people are not well represented in materials. The Educational Products Information Exchange (EPIE) Institute (1975) has produced a comprehensive materials assessment instrument that should assist educators as they consider many of these important points.

ical skills and concepts better through the use of active games rather than traditional approaches (Taylor \& Watkins, 1974). Teacher-made games may be utilized. For instance, a mock industrial facility might be created in one corner of the classroom. Students may role play the employees of the industry and do the math those employees would do. Also, teachers might construct self-correcting games that involve knowledge of math concepts, such as one with a gameboard that can be traversed only as participants provide correct answers to math problems.

The following list suggests math materials that appear' to present mathematical information in a functional way. The authors are not endorsing or judging these products, and the list is not intended to be all-inclusive. It is provided as a starting point for teachers.

\section{ACCENT/CONSUMER EDUCATION}

Follett

Chicago, IL

These booklets present some of the math concepts and social skills needed to function within our society. Topics include understanding consumer credit, budgeting and buying, and insuring life, income, and property.

\section{CONSUMER EDUCATION}

Interpretive Education

Kalamazoo, MI

This series acquaints the student with methods of wise shopping. It includes tags and labels, shopping values, bargain hunting, and reading ads.

\section{IT'S YOUR MONEY}

Steck-Vaughn

Austin, TX

A consumer guide to money management is the subject of this two-volume worktest. Exercises concentrate on taxes, budgeting, and credit buying.

\section{MATHEMATICS IN DAILY LIVING}

Steck-Vaughn

Austin, TX

This four-book consumable series helps build competency in basic math skill through adult topics.

\section{MONEY MATTERS}

Janus Book Publishers

Hayward, CA

This new workbook series allows students to apply skills in a functional way. Topics include budgeting, checking accounts, comparative shopping, and ad reading.

\section{PACEMAKER PRACTICAL ARITHMETIC SERIES}

Fearon-Pitman

Belmont, CA

Practical problems and exercises reinforce arithmetic skills. The series has three worktexts.

\section{REAL-LIFE MATH}

Hubbard, Inc.

Northbrook, IL

A multi-media program, this kit presents banking and business skills. Activities include student simulation of business and banking transactions while practicing basic arithmetic computations. 


\section{SEQUENTIAL MATH}

Harcourt, Brace, Jovanovich

New York, NY

This material can be used individually by either readers or nonreaders to reinforce math skills.

\section{TARGET MATH SERIES}

Mafex, Inc.

Johnstown, PA

The focus of this series of worktexts is on math concepts needed for independent living. Topics include using the bank, credit, time cards, spending money, math for family finances, and other functional math concepts.

\section{ASSESSMENT IN MATHEMATICS}

According to PL 94-142, each handicapped student is entitled to an Individualized Education Plan (IEP). This means that each handicapped student is to have specific annual goals and short-term objectives for each subject, including mathematics competencies. It sometimes becomes a difficult task because of the wide range of abilities and aptitudes among the mildly handicapped population. Consequently, teachers should begin this task by determining the current level of mathematical competence for each student. Then, planning for individualized instruction in mathematics may ensue. Determining the present level of math skill can be accomplished in several ways. One method is to use commercially produced math assessment instruments; another is to use teacher-made, criterion referenced texts.

\section{Commercially-produced Assessment Instruments}

At this time there seem to be a paucity of test instruments in mathematics, especially at the secondary level. In reviewing the tests available, they appear to generally reflect the content of regular elementary and secondary math programs. They are also normed on the performance of typical children. These instruments can be useful for global information about mathematical competency and for determining certain diagnostic information.
Some of the commercial tests may be useful in ascertaining the students' present level of math functioning at the beginning of the school year. The Key Math Diagnostic Arithmetic Test (Connolly, Nachtman, \& Pritchett, 1971), for example, can be used to test in three areas: content, operations, and applications. This instrument has been found to be especially well suited to the needs of educable mentally retarded students (Peterson, 1973).

Another instrument, the Stanford Diagnostic Mathematics Test (Beatty, Madden, \& Gardner, 1976), is a group-administered test that measures mathematical concepts and skills and covers four levels ranging from grade level 1.5 to high school. It can be useful in diagnosing specific strengths and weaknesses (Salvia \& Ysseldyke, 1978).

Diagnosis: An Instructional Aid in Mathematics (Guzaitis, Carlen, \& Juda, 1972) is a criterion referenced system designed to assess specific mathematical skills. It appears to help the classroom teacher in planning appropriate instruction (Boros, 1972).

These tests may be useful in gaining global information or concluding appropriate student placement, but they do not really measure the student's practical use of those mathematical concepts. Such tests also contain items that may be too difficult and complex for many handicapped students. Often the handicapped student has not been exposed to the same experiences as the children on whom the test was normed; consequently, the test may not be suitable for use with a handicapped population (Algozzine \& McGraw, 1979).

\section{Informal Mathematics Evaluation}

Teachers may find this second option more appropriate for individualizing instruction. It entails developing and using informal criterion referenced assessments. They can be developed from any amount of information to be taught in a course or in a weekly lesson. Often, they are used as pretests; then, the same or a matched assessment can be used as a posttest, to reflect the competencies developed as a result of the instruction.

Results from these tests can reveal if the instruction has been appropriate or if changes or modifications are needed. If the assessment shows that the student has not attained competency in a certain area, the teacher can review methods, materials, and objectives to determine 
if instruction has been appropriately planned and presented. In developing assessments teachers should keep in mind that the test should be easy to administer and score, have items clearly stated and correct, be well organized and sequenced, have items that adequately evaluate student competency, and have appropriate criterion referenced questions.

A sample criterion referenced, teacher-made assessment item is provided in Figure 3. It closely follows the format of Figure 2 so that the teacher can readily make a determination of students' strengths and weaknesses in the suggested functional math sequence.

\section{CONCLUSION}

The goal of providing a meaningful, realistic math program to handicapped learners is shared by the vast majority of educators. The approach suggested here should help teachers evaluate and modify their math programs to provide a more functional math curriculum that is both meaningful and realistic to handicapped adolescents.

The reasons to learn math, stressed by a functional math program, should help pupils become excited and motivated to learn. Realism in content, learning activities, and materials is also important toward instilling in pupils the desire to learn. With a focus on the use of math for satisfying one's real life needs, pupil motivation should follow. As handicapped adolescents request more work and ask or demand to be taught new skills so they can solve realistic problems, teachers will know that these pupils are being well prepared for their futures.

\section{REFERENCES}

Algozzine, R., \& McGraw, K. Diagnostic testing in mathematics: An extension of the PIAT? Teaching Exceptional Children, 1979, 12, 71-77.

Beattie, J. R., \& Schwartz, S. E. Readability of special education math books. The Pointer, 1979, 23, 43-46.

Beatty, L. S., Madden, R., \& Gardner, E. F. Stanford diagnostic mathematics test. New York: Harcourt Brace Jovanovich, 1978.
Budd, D. M. Secondary programs for exceptional students: A survey of resources, Orlando, FL: Florida Learning Resource System, 1979.

Buffer, J. J., \& Miller, P. W. The effects of selected industrial arts activities on educable mentally retarded students' achievements and retention of metric linear concepts. Journal of Industrial Teacher Education, 1976, 15, 7-16.

Boros, D. K. (Ed.) Seventh mental measurements yearbook. Highland Park, NJ: Gryphon Press, 1972, pp. 842-890.

Brolin, D. E., \& Kokaska, C. J. Career education for handicapped children and youth. Columbus, $\mathrm{OH}$ : Charles E. Merrill Publishing Co., 1979.

Clark, G. M. Career education: A concept - A challenge. In S. E. Schwartz (Ed.), Institute on career education for the handicapped. University, AL: Project Retool, 1980.

Connolly, A., Nachtman, W., \& Pritchett, E. Manual for the key' math diagnostic arithmetic test. Circle Pines, MN: American Guidance Service, 1971.

Dunn, L. M. (Ed.). Exceptional children in the schools: Special education in transition. New York: Holt, Rinehart \& Winston, 1973.

Educational Products Information Exchange (EPIE) Institute. EPIE career education SET (Vol. 1 \& 2). New York: Author, 1975.

Finn, P., \& Brown J. Career education and the mathematics classroom. Mathematics Teacher, 1977, 70, 489-496.

Fry, E. Fry's readability graph: Clarification, validity and extension to level 17. Journal of Reading, 1977, 21, 242-252.

Guzaitis, J., Carlin, J. A., \& Juda, S. Diagnosis: An instructional aid (mathematics). Chicago: Science Research Associates, 1972.

Krause, E. F. Mathematics for elementary teachers. Englewood Cliffs, NJ: Prentice-Hall, 1978.

Martin, E. W. Individualism and behaviorism as future trends in educating handicapped children. Exceptional Children, 1972, 38, 517-525.

McDowell, R. L., \& Brown, G. W. The emotionally disturbed adolescent: Development of program alternatives in secondary education. Focus on Exceptional Children, 1978, 10, 1-15.

Peterson, D. Functional mathematics for the mentally retarded. Columbus, OH: Charles E. Merrill Co., 1973.

Rigger, T. J., \& Rigger, S. W. Mathematics for vocational rehabilitation of secondary EMH students. Journal of Special Education, $1980,16,117-126$.

Salvia, J., \& Ysseldyke, J. E. Assessment in special education and remedial education. Boston: Houghton Mifflin Co., 1978.

Schwartz, S. E. Real-life math, Chicago: Hubbard Publishers, 1977.

Sengstock, W. L., \& Wyatt, K. E. The metric system and its implications for curriculum for exceptional children. Teaching Exceptional Children, 1976, 8, 58-65.

Taylor, G. R., \& Watkins, S. T. Active games: An approach to teaching mathematics skills to the educable mentally retarded. Arithmetic Teacher, 1974, 21, 674-678.

Trace, M. W., Cuvo, A. J., \& Criswell, J. L. Teaching coin equivalence to the mentally retarded. Journal of Applied Behavior Analysis, 1977, 10, 85-92.

U.S. Department of Commerce. Statistical abstract of the United States. Washington, DC: Bureau of the Census, 1979.

U.S. Department of Labor. Dictionary of occupational titles (4th ed.). Washington, DC: U.S. Government Printing Office, 1977.

Vitello, S. J. Quantitative abilities of mentally retarded children. Education \& Training of the Mentally Retarded, 1976, 11, 125-129. 
Annual Goal: Banking and Consumer Skills

Specific Goal: Student will correctly compute new account balance after writing a check.

Problem:

You now have $\$ 21.75$ in your checking account. If you write a check for $\$ 9.70$ to pay for a new shirt, how much will you have left in your checking account?

1. Do you think you will need to do problems like this when you're an adult?

Circle one: Yes No Maybe

2. What does the problem ask?

Check one: How much you spent for the shirt. How much you will have after buying the shirt. How much you started with in your account.

3. Circle the operation you need to use.
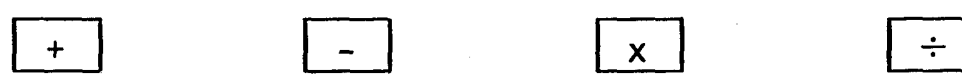

4. Check the answer you think is about right.

$\$ 12.00$

$\$ 30.00$

$\$ 21.00$

5. Do your math work here:

6. Check your answer here.

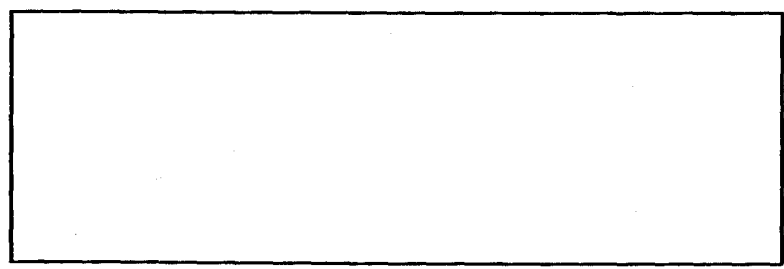

Answer

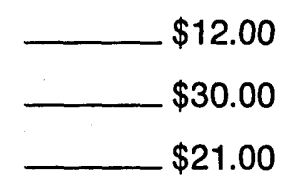

